\title{
NOVEL THERMAL INSULATION WITH GAS-FILLED CAVITIES - ASSESSMENT OF THERMAL PERFORMANCE OF DIFFERENT DESIGNS BASED ON NUMERICAL SIMULATIONS OF HEAT TRANSFER
}

\author{
MIHA JUKIĆ ${ }^{1}$, SABINA JORDAN ${ }^{1}$, DANIJEL LISIČIĆ ${ }^{2}$ \\ ${ }^{1}$ Slovenian National Building and Civil Engineering Institute, Slovenia. \\ 2 JUB d.o.o., Technology research centre, Slovenia.
}

\begin{abstract}
Not only is the energy efficiency of buildings nowadays becoming more and more important; the legislative requirements, the people's awareness of the environmental questions and their thermal comfort expectations are also on a much higher level. All of these issues can be addressed by making the building envelope more thermally resistant. However, with the traditional thermal insulation materials the thickness of thermal insulation layers is already at the viable limits. Therefore, the development of new, more efficient thermal insulation products with a higher thermal resistance is highly promoted. Preliminary research results can be applied to models to develop and confirm the conceptual designs of such new materials. In this paper, an analysis of thermal performance is presented for a novel thermal insulation consisting of graphite polystyrene (GPS) matrix with cavities filled with an insulative gas, and a protective sheath to prevent it from leaking. Bearing in mind the suitability for later production, different configurations of the assembly were considered, regarding the matrix geometry, the type of the gas filling, and the surface emissivity of the cavities. A range of numerical simulations of heat transfer was conducted to determine the efficiency of different designs in reducing the conductive, the convective, and the radiative heat transfer. Advantages, limitations and some detailed parameters of the proposed design concepts were determined, which were then used for optimisation. The analysis of the results indicates that the equivalent thermal conductance of a GPS panel can be significantly reduced by the introduction of gas-filled cavities. The reduction is highly dependent on the type of the gas filling (thermal conductivity, viscosity, specific heat, etc.), the size of the cavities, and the cavity surface emissivity. Keywords: gas-filled cavities, graphite polystyrene, numerical simulation, thermal insulation.
\end{abstract}

\section{INTRODUCTION}

Energy conservation has become an issue of increasing importance over the last few decades and, under the pressing requirements to improve energy efficiency, the growing thickness of the building envelope is becoming a restrictive factor. With thermal conductivity of the conventional insulation materials at their viable limits, development of advanced, superior insulation systems or materials is required [1]. Various alternatives include for instance vacuum insulation panels [2], nanofoams, e.g. aerogel [3], and gas-filled panels [4], [5].

Gas-filled panels (GFPs) are an interesting option, composed of three main components: a core with cavities, a gas filling, and a protective sheath. The gas filling with a thermal conductivity lower than that of air, significantly reduces the conductive heat transfer through the panel. The core, which also gives form to the GFP, is used to prevent or reduce convection and to diminish radiative heat transfer, while the protective sheath keeps the gas from leaking and being substituted by air, which would result in a reduced thermal resistance of the GFP.

Although the idea itself is not new [6], GFPs are a fairly recent addition to the market and still subject to research and development. In commercial products ([7], [8]), the baffle (core) is usually constructed from multiple sheets of metalized polymer foil while, to the authors' knowledge, no GFP design based on an expanded polystyrene core is currently available. The latter would provide more firmness to the panel, which could be useful, e.g. in ETICS façade systems. 
The objective of the present study was to propose a range of possible GFP designs and examine their thermal performance using numerical simulations of heat transfer in order to determine the optimal configuration and evaluate the improvement of the proposed design over the plain GPS panel. The designs under consideration varied in the geometry of the graphite polystyrene (GPS) core, the gas filling, and the cavity surface emissivity. Attention was given to detail, such as cavity size and shape, as well as heat flow direction. The numerical model used for the simulations was validated with an experiment.

\section{METHODOLOGY}

Bearing in mind the suitability for later production, four geometries of the graphite polystyrene (GPS) matrix were chosen and combined with different gas fillings and surface emissivities of the matrix cavities. A numerical simulation of heat transfer was performed for each configuration, using a numerical model validated by experimental measurements. Two physical directions of heat flow were considered - the panel could be exposed either to horizontal or to upward heat flow, corresponding to installation of the panel in a wall or in a ceiling, respectively. Finally, the equivalent thermal conductivity of each panel was calculated.

Next, two of the chosen geometries were modified so as to share the shape and the size of the cavities, while differing in their alignment. The influence of cavity alignment on the intensity of different forms of heat transfer was examined through additional numerical simulations, performed for selected GFP configurations.

The last task was the optimisation of cavity size in regard to convection, i.e. the greatest cavity size to suppress convection, for various gas fillings and two heat flow directions. The influence of the temperature gradient was considered as well.

\subsection{Geometry, gas fillings, emissivities}

Cross sections of the four chosen geometries are shown in Fig. 1, their outer dimensions are $40 \mathrm{~cm} \times 8 \mathrm{~cm}$. The long sides are exposed to external and internal environments, so the heat flow is parallel with the short sides. The maximum dimensions of individual cavities in the direction of the heat flow, which importantly affect the thermal performance of the insulation, are as follows:

Corner cavities in geometry 1 adjacent to the long and the short edges of the cross section are $5 \mathrm{~mm}$ and $20 \mathrm{~mm}$ thick, respectively. Thickness of the elongated central cavities is $15 \mathrm{~mm}$,

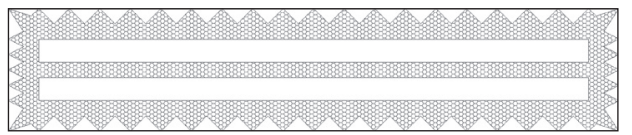

Geometry 1

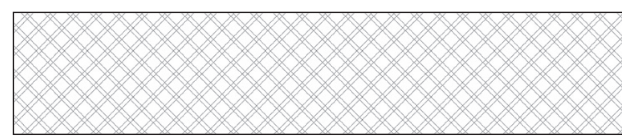

Geometry 3

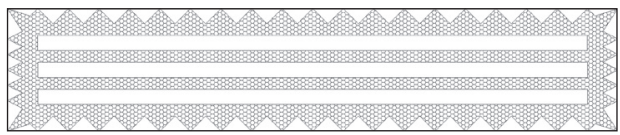

Geometry 2

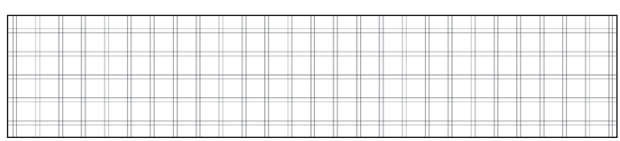

Geometry 4

Figure 1: Geometries of graphite polystyrene matrices under consideration. 
and of all the remaining cavities, $10 \mathrm{~mm}$. Geometry 2 is identical, only the two central cavities are replaced by three thinner ones of thickness $10 \mathrm{~mm}$.

Diagonals of the diamond-shaped cavities in geometry 3 measure $11.5 \mathrm{~mm}$. The cropped cavities next to the long edges of the cross-section are $8.2 \mathrm{~mm}$ thick. The square cavities in geometry 4 have sides of $12.5 \mathrm{~mm}$, the rectangular cavities near the long edges are $8.8 \mathrm{~mm}$ thick.

Due to the different sizes of square- and diamond-shaped cavities in geometries 4 and 3, the two cannot be directly compared. For this reason, modified geometries $4 \mathrm{a}$ and $3 \mathrm{a}$ have been analysed as well, both of them having cavities with sides of $10 \mathrm{~mm}$.

The described GPS matrices were combined with five different gas fillings. Despite the superior performance, krypton $(\mathrm{Kr})$ and xenon $(\mathrm{Xe})$ were discarded after initial testing, due to excessive price. Further analyses were performed with argon (Ar), carbon dioxide $\left(\mathrm{CO}_{2}\right)$ and air. Also, three treatments of cavity surfaces have been considered: untreated surfaces with emissivity equal to that of GPS $(\varepsilon=0.75)$, surfaces with a low emissivity finish $(\varepsilon=0.05)$, and an intermediate variant $(\varepsilon=0.30)$.

\subsection{Numerical modelling}

Numerical simulations of steady-state heat transfer were conducted using Physibel Bisco 11.0 software. Thermal conductivity of graphite polystyrene was $\lambda_{\mathrm{GPS}}=0.031 \mathrm{~W} / \mathrm{mK}$ and its surface emissivity, $\varepsilon_{\mathrm{GPS}}$, took three different values $(0.75,0.30,0.05)$. According to standard [9], the contribution of thin polymer layers to the thermal resistance of a building element may be neglected. For this reason, the metalized polymer foil forming the protective sheath was only modelled as a boundary between the outer cavities and the (internal or external) environment at the long edges of the panel. The surface emissivity at this boundary was $\varepsilon=0.05$.

Unventilated cavities were treated in accordance with the radiosity method, described in standard [10]. In this method a cavity is replaced by transparent material, the thermal conductivity of which accounts for the convective heat transfer through the cavity. The radiative heat transfer is calculated separately, depending on the geometry of the cavity and on the temperatures and the emissivities of individual surfaces.

Thermal conductivity of the substitute material was calculated as the conductivity of still gas, multiplied by the Nusselt number $(\mathrm{Nu})$, which describes the intensity of convection. The value of $\mathrm{Nu}$ was determined according to standard [11], depending on the type of the gas filling, the physical direction of the heat flow, and the maximum dimensions of the cavity parallel with the heat flow. Thermophysical properties of the gas fillings, collected in Table 1, were taken from standard [11], except for the properties of $\mathrm{CO}_{2}$ which were taken from [12].

Table 1: Thermophysical properties of gas fillings at $10^{\circ} \mathrm{C}$.

\begin{tabular}{lcccc}
\hline Gas & $\begin{array}{c}\text { Density } \\
{\left[\mathrm{kg} / \mathbf{m}^{3}\right]}\end{array}$ & $\begin{array}{c}\text { Dynamic viscosity } \\
{[\mathrm{kg} / \mathbf{m s}]}\end{array}$ & $\begin{array}{c}\text { Conductivity* } \\
{[\mathbf{W} / \mathbf{m K}]}\end{array}$ & $\begin{array}{c}\text { Specific heat capacity } \\
{[\mathbf{J} / \mathbf{k g K}]}\end{array}$ \\
\hline Air & 1.232 & $1.761 \times 10^{-5}$ & $2.496 \times 10^{-2}$ & 1008 \\
$\mathrm{Ar}$ & 1.699 & $2.164 \times 10^{-5}$ & $1.684 \times 10^{-2}$ & 519 \\
$\mathrm{CO}_{2}$ & 1.882 & $1.414 \times 10^{-5}$ & $1.541 \times 10^{-2}$ & 833 \\
$\mathrm{Kr}$ & 3.560 & $2.400 \times 10^{-5}$ & $0.900 \times 10^{-2}$ & 245 \\
$\mathrm{Xe}$ & 5.689 & $2.226 \times 10^{-5}$ & $0.529 \times 10^{-2}$ & 161 \\
\hline
\end{tabular}

* Thermal conductivity of still gas (no convection) 
Table 2: Boundary conditions used in numerical simulations.

\begin{tabular}{lcc}
\hline & Temperature $\left[{ }^{\circ} \mathbf{C}\right]$ & $\begin{array}{c}\text { Surface resistance } \\
{\left[\mathbf{m}^{2} \mathbf{K} / \mathbf{W}\right]}\end{array}$ \\
\hline External edge of the GFP panel & 0 & 0.001 \\
Internal edge of the GFP panel & 20 & 0.001 \\
\hline
\end{tabular}

The boundary conditions, imposed at the external and internal (long) sides of the panel, are listed in Table 2. Since the panels are not intended to be exposed directly to external or internal environments, a very low value was used for the surface resistance, simulating contact with another material. The short sides of the panel are adiabatic.

The surface thermal resistances in Table 2 were chosen according to our experience and are approximate, rather than exact values. However, their influence on the results of the analysis has proven insignificant. In a representative numerical simulation, an increase of the surface resistance by an exaggerated factor 10 (to $0.01 \mathrm{~m}^{2} \mathrm{~K} / \mathrm{W}$ ) resulted in a reduction of the panel's equivalent thermal conductivity, $\lambda_{\text {eq }}$, by less than $1 \%$. Reduction of the resistance by the same factor (to $0.0001 \mathrm{~m}^{2} \mathrm{~K} / \mathrm{W}$ ) had an even smaller effect, with an increase of $\lambda_{\text {eq }}$ by less then $1 \%$.

\subsection{Modification of geometries 3 and 4}

Geometries 3 and 4, proposed by the potential manufacturer of the GFPs, do not allow an objective comparison of panels with square- and diamond-shaped cavities because of the unequal side lengths of their cavities $(12.5 \mathrm{~mm}$ and $8.1 \mathrm{~mm}$, respectively). For this reason, modified geometries $3 \mathrm{a}$ and $4 \mathrm{a}$ were devised as meshes of $10 \mathrm{~mm} \times 10 \mathrm{~mm}$ cavities divided by walls of thickness $3 \mathrm{~mm}$, differing only in the alignment of the cavities - in geometry $4 \mathrm{a}$ the sides of the cavities are parallel with the sides of the panel, whereas in geometry $3 a$ they are rotated by $45^{\circ}$.

Numerical simulations of heat transfer through GFPs with the modified geometries were performed for horizontal heat flow and air as the gas filling, giving special attention to different forms of heat transfer. In the basic numerical model (A) conduction through the GPS matrix, as well as radiation and convection through the cavities, were considered. In the following two models, the heat was transferred through the cavities only by radiation (B) or only by convection (C). In the final model (D), heat transfer through cavities was prevented completely (simulating vacuum and zero emissivity of cavity surfaces), allowing only conduction through GPS.

The influence of cavity size on the efficiency of geometries 3a and $4 \mathrm{a}$ was of interest as well, so the simulations were repeated for the panels, scaled by factors 2 and 4 . Note that the wall thickness and the panel dimensions were increased accordingly.

\subsection{Calculation of optimal cavity sizes in regard to convection}

Intensity of convection in a cavity is largely determined by its size. If the cavity is small enough, convection is prevented and the heat is transferred through still gas by conduction. Optimal cavity dimensions, i.e. the largest that still prevent convection, were determined for two cavity shapes (square and diamond), five gas fillings (air, $\mathrm{CO}_{2}, \mathrm{Ar}, \mathrm{Kr}, \mathrm{Xe}$ ), and two directions of the heat flow (horizontal and upward).

For each combination of the above elements, the Nusselt number $(\mathrm{Nu})$, defined as the ratio between the convective and the conductive heat transfer, was calculated in accordance with 
standard [11]. The side length of the cavity was varied until finding the largest value to ensure $\mathrm{Nu}=1$ (absence of convection) and then rounded down to the nearest $\mathrm{mm}$. The temperature gradient was assumed as constant throughout the panel and computed from the boundary temperatures in Table 2 and the thickness of the GFP. Several panel thicknesses were considered in the cases of air and $\mathrm{CO}_{2}$.

\subsection{Validation of the numerical model}

The numerical model was validated by measurements of heat transfer through a prototype GFP with geometry 1 (Fig. 2). The GPS matrix of the prototype contained air and was enclosed in a metalized polyester foil. The two elongated central cavities were lined with aluminium foil to ensure low emissivity, while the triangular cavities along the perimeter remained untreated. The dimensions of the panel were $400 \mathrm{~mm} \times 400 \mathrm{~mm} \times 75 \mathrm{~mm}$.

The equivalent thermal conductivity, $\lambda_{\text {eq }}$, of the prototype GFP was measured in an accredited laboratory by the heat flow meter method according to standard [13]. The measurement was performed in a single-specimen symmetrical configuration - with heat flow meters on both sides of the specimen. The dimensions of the hot and cold plates of the apparatus were $80 \mathrm{~cm} \times 80 \mathrm{~cm}$, and the size of the metering area was $16 \mathrm{~cm} \times 16 \mathrm{~cm}$.

The measured value $\lambda_{\text {eq }}=0.0314 \mathrm{~W} / \mathrm{mK}$ pertains to the central area of the panel where the heat flux was measured and does not include the linear thermal bridge along the edges of the panel.

The experiment was replicated as closely as possible in the numerical model. The model was shortened so as not to include the thermal bridges near the adiabatic sides of the panel, i.e. the central cavities span the whole width of the model. Furthermore, the tips of the original geometry 1 (Fig. 1) were removed to match the thickness of the specimen $(75 \mathrm{~mm}$ instead of the original $80 \mathrm{~mm}$ ).

The temperatures at the top and the bottom sides of the panel were set to $27.5^{\circ} \mathrm{C}$ and $14.5^{\circ} \mathrm{C}$, respectively, to match the measurement conditions in the heat flow meter. The increased average temperature $\left(21^{\circ} \mathrm{C}\right)$ required the adjustment of the thermal conductivity of graphite polystyrene to $\lambda_{\mathrm{GPS}}=0.032 \mathrm{~W} / \mathrm{mK}$, in accordance with standard [14]. Similarly, the thermal conductivity of air was increased to $\lambda_{\text {air }}=0.0258 \mathrm{~W} / \mathrm{mK}$. According to standard [11], convection is negligible in the case of downward heat flow.

Low emissivity, $\varepsilon_{\mathrm{AL}}=0.05$, was only applied to the surfaces of the elongated central cavities, covered in aluminium, while the emissivity $\varepsilon_{\mathrm{GPS}}=0.75$ was assigned to the untreated GPS surfaces of the triangular cavities. The emissivity of the metalized polyester foil closing the triangular cavities was estimated to $\varepsilon_{\mathrm{MPE}}=0.45$ using a thermographic camera FLIR B425.
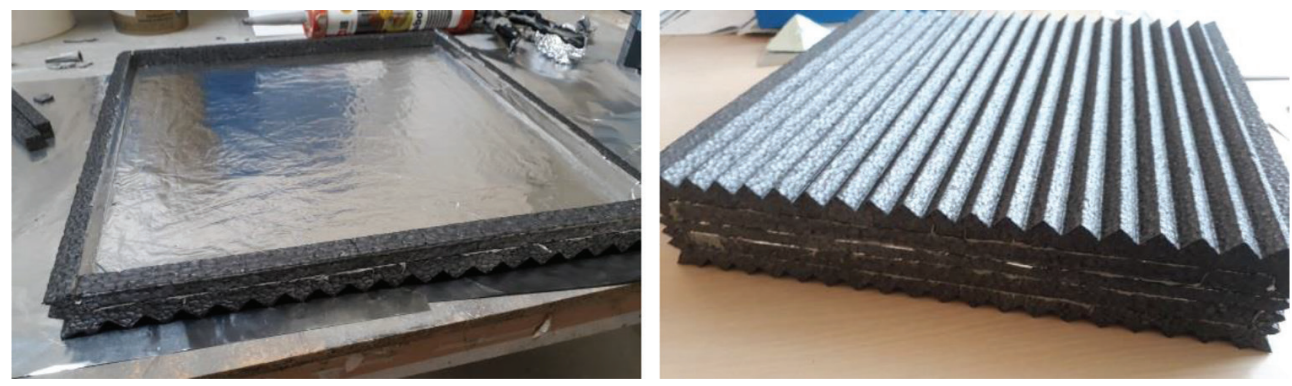

Figure 2: Prototype of a gas-filled panel with geometry 1. 
The following procedure was used to determine $\varepsilon_{\mathrm{MPE}}$. The metalized polyester foil was maintained at a constant temperature, $\mathrm{T}_{\mathrm{MPE}}$, measured by a thermocouple. The emissivity setting, $\varepsilon_{\mathrm{IR}}$, of the thermographic camera was then altered until the temperature reading on the camera equalled $\mathrm{T}_{\mathrm{MPE}}$. The final value of $\varepsilon_{\mathrm{IR}}$ was taken as the emissivity of the specimen $\left(\varepsilon_{\mathrm{MPE}}=\varepsilon_{\mathrm{IR}}\right)$. Due to the limited precision of this approach, the influence of $\varepsilon_{\mathrm{MPE}}$ on the results of the numerical analysis had to be tested. Alteration of $\varepsilon_{\mathrm{MPE}}$ by \pm 0.05 (to 0.4 or 0.5 ) changed the final result $\left(\lambda_{\text {eq }}\right)$ by $1 \%$. Extreme alteration $\left(\varepsilon_{\mathrm{MPE}}\right.$ equal to 0.05 or 0.9$)$ changed it by $1 \%$. Considering the minimal influence of $\varepsilon_{\mathrm{MPE}}$ on the simulation results, the applied procedure is deemed adequate.

The equivalent thermal conductivity of the prototype GFP, determined by the numerical simulation, took the value of $\lambda_{\text {eq }}=0.0307 \mathrm{~W} / \mathrm{mK}$ which is approximately $2 \%$ lower than the measured value. The numerical simulation was performed twice, once applying the surface thermal resistances from Table 2, and once applying no surface resistance. The results differed by only $1 \%$, implying irrelevance of this boundary condition for the case in question.

\section{RESULTS OF NUMERICAL SIMULATIONS}

\subsection{Gas-filled panels exposed to horizontal heat flow}

Equivalent thermal conductivities, $\lambda_{\text {eq }}$, obtained by numerical modelling of GFPs subject to horizontal heat flow, are collected in Table 3 . The results depend on the chosen geometry of the GPS matrix, the gas filling, and the emissivity, $\varepsilon$, of cavity walls. The shaded fields represent the GFP configurations that exhibit better thermal performance than a simple GPS panel of equal thickness $\left(\lambda_{\text {eq }}<\lambda_{\mathrm{GPS}}=0.031 \mathrm{~W} / \mathrm{mK}\right)$. In other cases, cavities have a negative effect on the performance of the panel.

The cavities of all four core geometries in Fig. 1 are small enough to prevent development of convection, regardless of being filled with air, $\mathrm{CO}_{2}$, or Ar. In each case the equivalent thermal conductivity of the transparent substitute material is equal to the appropriate conductivity of still gas, specified in Table 1 , which is always lower than $\lambda_{\mathrm{GPS}}$. If the convective heat transfer alone were considered, all GFPs would perform better than a simple GPS panel. This is confirmed by the simulations employing low cavity surface emissivity $(\varepsilon=0.05)$.

In radiative heat transfer, however, the cavities in the GPS core have a negative influence on its thermal performance because the temperature difference within a cavity is much greater than in the micro-pores of GPS, which results in significantly increased heat transfer. In the case of non-treated cavity surfaces $(\varepsilon=0.75)$ this effect prevails over the benefit in conductive-convective heat transfer, regardless of the geometry and the gas filling. The effect can be mitigated by lowering the cavity surface emissivity. Using $\mathrm{CO}_{2}$ or argon, $\varepsilon=0.30$ already ensures net reduction of equivalent thermal conductivity (compared to $\lambda_{\mathrm{GPS}}$ ) but the improvement is relatively small. With air, a less effective insulator, this is only achieved with $\varepsilon=0.05$.

Table 3: Equivalent thermal conductivity, $\lambda_{\text {eq }}[\mathrm{W} / \mathrm{mK}]$, of GFPs, depending on the gas filling and the cavity surface emissivity, in the case of horizontal heat flow.

\begin{tabular}{lcccccccccc}
\hline Gas filling & \multicolumn{3}{c}{ Air } & \multicolumn{3}{c}{$\mathbf{C O}_{\mathbf{2}}$} & \multicolumn{3}{c}{ Ar } \\
Emissivity & $\mathbf{0 . 7 5}$ & $\mathbf{0 . 3 0}$ & $\mathbf{0 . 0 5}$ & $\mathbf{0 . 7 5}$ & $\mathbf{0 . 3 0}$ & $\mathbf{0 . 0 5}$ & $\mathbf{0 . 7 5}$ & $\mathbf{0 . 3 0}$ & $\mathbf{0 . 0 5}$ \\
\hline Geometry 1 & 0.039 & 0.033 & 0.029 & 0.036 & 0.029 & 0.024 & 0.036 & 0.029 & 0.024 \\
Geometry 2 & 0.037 & 0.032 & 0.029 & 0.034 & 0.027 & 0.023 & 0.034 & 0.028 & 0.024 \\
Geometry 3 & 0.038 & 0.032 & 0.029 & 0.033 & 0.026 & 0.022 & 0.034 & 0.027 & 0.023 \\
Geometry 4 & 0.044 & 0.035 & 0.029 & 0.038 & 0.028 & 0.021 & 0.039 & 0.029 & 0.022 \\
\hline
\end{tabular}


The best results are obtained with the lowest emissivity $(\varepsilon=0.05)$ in combination with $\mathrm{CO}_{2}$ or Ar, giving an approximately $30 \%$ lower conductivity than that of plain GPS.

Expectedly, geometry 2 outperforms geometry 1, but not by much (5-7\% at $\varepsilon=0.75$ and $1-3 \%$ at $\varepsilon=0.05)$. Geometry 3 is slightly better. An interesting phenomenon is observed with geometry 4 which, at low emissivity, exhibits the best performance of all geometries, while performing worst at high emissivity. This implies that it is relatively ineffective against radiative, and more effective against convective heat transfer.

Figure 3 displays the temperature field (a) and the heat flux field (b) for the panel with geometry 1 , filled with $\mathrm{CO}_{2}$, and with cavity surface emissivity $\varepsilon=0.05$.

\subsection{Gas-filled panels exposed to upward heat flow}

Upward heat flow, with a high temperature at the bottom of the cavity and a low temperature at the top, creates more favourable conditions for the onset of convection, especially in cavities with a greater characteristic dimension and/or temperature gradient. Convection accelerates heat transfer through the cavity, i.e. increases the equivalent thermal conductivity of the substitute material in the numerical model. Radiative heat transfer, on the other hand, is unaffected by the direction of the heat flow.

In geometry 1 convection occurs in the four corner cavities, adjacent to the short sides of the panel, and in the two elongated central cavities. The increase of the equivalent conductivity of these cavities is most obvious in the case of $\mathrm{CO}_{2}$, due to its low viscosity and high density. Smaller thickness of the central cavities in geometry 2 prevents convection in the cases of air and $\mathrm{Ar}$, and reduces it substantially in the case of $\mathrm{CO}_{2}$. Small cavities in geometry 3 ensure

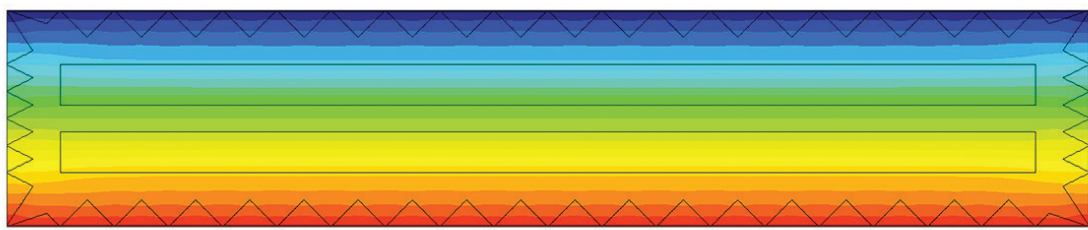

(a)
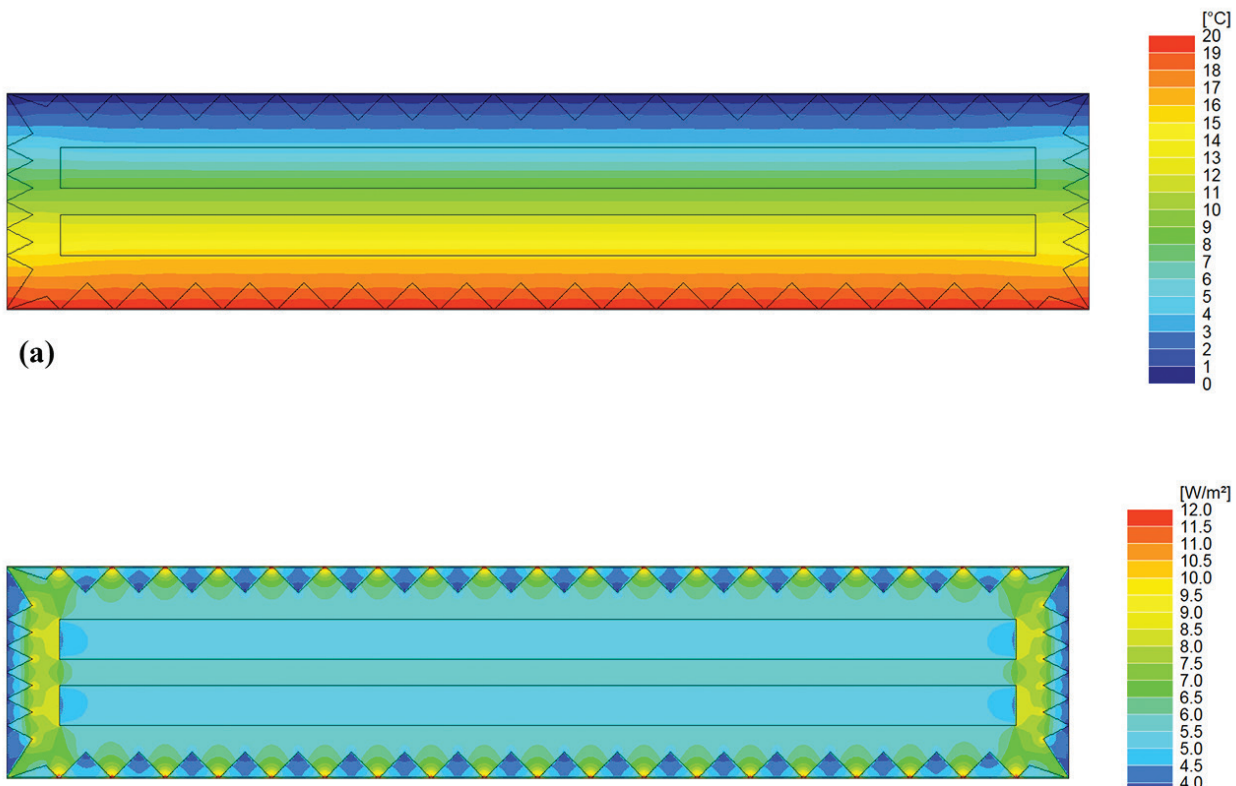

(b)

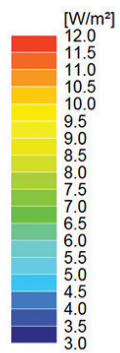

Figure 3: Graphical output of the numerical simulation for geometry 1, gas filling $\mathrm{CO}_{2}$, cavity surface emissivity $\varepsilon=0.05$, and horizontal heat flow. (a) Temperature field; (b) Heat flux field. 
absence of convection, regardless of the gas filling. The slightly bigger cavities in geometry 4 cannot prevent convection completely, especially if they are filled with carbon dioxide.

Occurrence of convection in the panels exposed to upward heat flow reflects in their reduced thermal resistance. Table 4 shows the equivalent conductivities of GFPs, depending on the geometry of the GPS matrix, the gas filling, and the cavity surface emissivity. The shaded fields represent the configurations that perform better than a plain GPS panel of the same thickness, i.e. $\lambda_{\text {eq }}<\lambda_{\mathrm{GPS}}=0.031 \mathrm{~W} / \mathrm{mK}$ (comparison was made before rounding the values of $\lambda_{\text {eq }}$ to three decimal places).

The advantage of geometry 2 over geometry 1 is now more apparent than in the case of horizontal heat flow. At low emissivity $(\varepsilon=0.05)$, the equivalent conductivity of the former is $7-14 \%$ lower, depending on the gas filling. The best thermal performance is observed in geometry 3 , while the cavities of geometry 4 prove a bit too big for optimal performance, especially if the gas filling is $\mathrm{CO}_{2}$.

Comparison of data from Tables 3 and 4 is given in Table 5 showing the relative increase of the equivalent conductivity of GFPs in the case of upward heat flow, compared to horizontal heat flow (computed before rounding the values of $\lambda_{\text {eq }}$ to three decimal places). Significant decline in thermal performance of geometry 1 is caused mostly by its relatively thick central cavities. Geometry 3 gives the same results for both heat flow directions, its cavities being small enough to prevent convection in all considered situations. As for geometries 2 and 4, substantial differences are only observed if the panels are filled with $\mathrm{CO}_{2}$ which, due to its thermophysical properties, requires smaller cavities to remain still.

\subsection{Comparison of panels with square- and diamond-shaped cavities}

The modified geometries $4 \mathrm{a}$ and $3 \mathrm{a}$, having equally sized but differently aligned cavities (square and diamond, respectively), are compared in Table 6. The presented equivalent

Table 4: Equivalent thermal conductivity, $\lambda_{\text {eq }}[\mathrm{W} / \mathrm{mK}]$, of GFPs, depending on the gas filling and the cavity surface emissivity, in the case of upward heat flow.

\begin{tabular}{lcccccccccc}
\hline Gas filling & \multicolumn{3}{c}{ Air } & \multicolumn{3}{c}{$\mathbf{C O}_{2}$} & \multicolumn{3}{c}{ Ar } \\
Emissivity & $\mathbf{0 . 7 5}$ & $\mathbf{0 . 3 0}$ & $\mathbf{0 . 0 5}$ & $\mathbf{0 . 7 5}$ & $\mathbf{0 . 3 0}$ & $\mathbf{0 . 0 5}$ & $\mathbf{0 . 7 5}$ & $\mathbf{0 . 3 0}$ & $\mathbf{0 . 0 5}$ \\
\hline Geometry 1 & 0.040 & 0.035 & 0.031 & 0.037 & 0.032 & 0.029 & 0.037 & 0.031 & 0.027 \\
Geometry 2 & 0.037 & 0.032 & 0.029 & 0.034 & 0.028 & 0.025 & 0.034 & 0.028 & 0.024 \\
Geometry 3 & 0.038 & 0.032 & 0.029 & 0.033 & 0.026 & 0.022 & 0.034 & 0.027 & 0.023 \\
Geometry 4 & 0.044 & 0.035 & 0.029 & 0.040 & 0.031 & 0.025 & 0.039 & 0.029 & 0.023 \\
\hline
\end{tabular}

Table 5: Relative increase in [\%] of the equivalent thermal conductivity of GFPs in the case of upward heat flow, compared to horizontal heat flow.

\begin{tabular}{lccccccccc}
\hline Gas filling & & Air & & \multicolumn{3}{c}{$\mathbf{C O}_{\mathbf{2}}$} & \multicolumn{3}{c}{ Ar } \\
Emissivity & $\mathbf{0 . 7 5}$ & $\mathbf{0 . 3 0}$ & $\mathbf{0 . 0 5}$ & $\mathbf{0 . 7 5}$ & $\mathbf{0 . 3 0}$ & $\mathbf{0 . 0 5}$ & $\mathbf{0 . 7 5}$ & $\mathbf{0 . 3 0}$ & $\mathbf{0 . 0 5}$ \\
\hline Geometry 1 & 1.0 & 3.6 & 7.1 & 3.1 & 11.1 & 21.4 & 1.1 & 4.9 & 11.3 \\
Geometry 2 & 0.0 & 0.0 & 0.0 & 1.2 & 4.1 & 8.8 & 0.0 & 0.3 & 0.3 \\
Geometry 3 & 0.0 & 0.0 & 0.0 & 0.0 & 0.0 & 0.0 & 0.0 & 0.0 & 0.0 \\
Geometry 4 & 0.0 & 0.0 & 1.1 & 6.0 & 11.6 & 18.9 & 0.2 & 1.4 & 3.9 \\
\hline
\end{tabular}


Table 6: Equivalent thermal conductivity, $\lambda_{\mathrm{eq}}[\mathrm{W} / \mathrm{mK}]$, of GFPs - comparison of square and diamond cavity geometries for different mechanisms of heat transfer and cavity sizes.

Cavity geometry Square (geometry 4a) Diamond (geometry 3a)

\begin{tabular}{lccccccc} 
Side length & & $\mathbf{1 0} \mathbf{~} \mathbf{m}$ & $\mathbf{2 0} \mathbf{~} \mathbf{m}$ & $\mathbf{4 0} \mathbf{~} \mathbf{m}$ & $\mathbf{1 0} \mathbf{~} \mathbf{m}$ & $\mathbf{2 0} \mathbf{~} \mathbf{m m}$ & $\mathbf{4 0} \mathbf{~} \mathbf{m}$ \\
\hline Model A: & $\varepsilon=0.75$ & 0.040 & 0.049 & 0.062 & 0.040 & 0.049 & 0.063 \\
cond + conv + rad & $\varepsilon=0.05$ & 0.029 & 0.030 & 0.038 & 0.029 & 0.030 & 0.039 \\
Model B: & $\varepsilon=0.75$ & 0.023 & 0.033 & 0.047 & 0.024 & 0.035 & 0.050 \\
cond + rad & $\varepsilon=0.05$ & 0.009 & 0.010 & 0.013 & 0.009 & 0.011 & 0.014 \\
Model C: cond + conv & 0.028 & 0.028 & 0.035 & 0.028 & 0.028 & 0.036 \\
Model D: cond & & 0.008 & 0.008 & 0.008 & 0.008 & 0.008 & 0.008 \\
\hline
\end{tabular}

thermal conductivities, $\lambda_{\text {eq }}$, were computed for three cavity sizes and for different forms of heat transfer (combinations of conduction, convection, and radiation). In the cases where heat is transmitted by radiation, results are given for two values of cavity surface emissivity, $\varepsilon=0.05$ and $\varepsilon=0.75$. The differences between the two geometries are small and, in many cases, cannot be observed from the rounded values in this table.

In model D, where heat is transferred by conduction through GPS alone, the thermal transmittance of the square geometry is $6 \%$ lower than that of the diamond geometry. The ratio is identical for all cavity sizes since the thickness of the GPS walls, the only conductor, grows proportionally with the whole panel.

If conductive-convective transfer through cavities is permitted as well (model C), the two geometries give more similar results. In the cases of cavities with side lengths of $10 \mathrm{~mm}$ and $20 \mathrm{~mm}$, which are small enough to prevent convection, the difference between them is negligible, meaning that the diamond geometry is slightly advantageous regarding convection. The $40 \mathrm{~mm}$ cavities, however, allow the development of convection which is stronger in geometry 3 a because of the larger temperature difference within the diamond cavities. Consequently, the increase of $\lambda_{\text {eq }}$ in comparison with model $\mathrm{D}$ is slightly larger than exhibited by geometry $4 \mathrm{a}$.

Numerical models A and B with low cavity surface emissivity $(\varepsilon=0.05)$ give results rather similar to those of models $\mathrm{C}$ and $\mathrm{D}$ (without radiation), especially for the smaller cavity sizes, hence the focus is set on the cases with $\varepsilon=0.75$. As shown by model B (vacuum in the cavities), thermal resistance of the panel decreases with the increasing size of its cavities. A greater side length implies a larger temperature difference across the cavity and, consequently, a more intensive radiative heat transfer. Geometry $4 \mathrm{a}$ (square) gives 5-6\% lower values for $\lambda_{\text {eq }}$ than geometry $3 \mathrm{a}$ (diamond). Addition of conduction-convection through cavities (model A) reduces the difference to $3 \%$ for the large cavities, and eliminates it completely for the small ones.

\subsection{Optimal cavity sizes in regard to convection}

The maximum dimensions of diamond and square cavities that prevent the occurrence of convection in a panel of thickness $80 \mathrm{~mm}$ are collected in Table 7. The calculated sizes depend on the heat flow direction and the chosen gas filling. In order to prevent convection in horizontal heat flow, the cavities should have side lengths smaller than approx. $20 \mathrm{~mm}$ if 
Table 7: Maximum side lengths, $d_{\max }[\mathrm{mm}]$, of square- and diamond-shaped cavities, which prevent convection, depending on the gas filling and the direction of the heat flow. Thickness of the GFP is $80 \mathrm{~mm}$.

\begin{tabular}{lccccc}
\hline \multicolumn{2}{l}{$\begin{array}{l}\text { Cavity geometry } \\
\text { Direction of heat flow }\end{array}$} & Horizontal & Upward & Horizontal & Upward \\
\hline Gas filling & Air & 21 & 12 & 20 & 11 \\
& $\mathrm{CO}_{2}$ & 15 & 8 & 14 & 8 \\
& $\mathrm{Ar}$ & 20 & 11 & 19 & 10 \\
& $\mathrm{Kr}$ & 15 & 8 & 14 & 7 \\
& $\mathrm{Xe}$ & 11 & 6 & 10 & 6 \\
\hline
\end{tabular}

Table 8: Maximum side lengths, $\mathrm{d}_{\max }[\mathrm{mm}]$, of square- and diamond-shaped cavities, which prevent convection, depending on the thickness of GFP, the direction of the heat flow, and the gas filling (air and $\mathrm{CO}_{2}$ ).

\begin{tabular}{|c|c|c|c|c|c|c|c|c|c|}
\hline \multirow{3}{*}{\multicolumn{2}{|c|}{$\begin{array}{l}\text { Cavity geometry } \\
\text { Direction of heat flow } \\
\text { Gas filling }\end{array}$}} & \multicolumn{4}{|c|}{ Square cavities } & \multicolumn{4}{|c|}{ Diamond cavities } \\
\hline & & \multicolumn{2}{|c|}{ Horizontal } & \multicolumn{2}{|c|}{ Upward } & \multicolumn{2}{|c|}{ Horizontal } & \multicolumn{2}{|c|}{ Upward } \\
\hline & & Air & $\mathrm{CO}_{2}$ & Air & $\mathrm{CO}_{2}$ & Air & $\mathrm{CO}_{2}$ & Air & $\mathrm{CO}_{2}$ \\
\hline \multirow{5}{*}{$\begin{array}{l}\text { Thickness } \\
\text { of GFP }\end{array}$} & $40 \mathrm{~mm}$ & 18 & 13 & 10 & 7 & 16 & 11 & 9 & 6 \\
\hline & $60 \mathrm{~mm}$ & 20 & 14 & 11 & 8 & 18 & 13 & 10 & 7 \\
\hline & $80 \mathrm{~mm}$ & 21 & 15 & 12 & 8 & 20 & 14 & 11 & 8 \\
\hline & $100 \mathrm{~mm}$ & 23 & 16 & 13 & 9 & 21 & 15 & 12 & 8 \\
\hline & $120 \mathrm{~mm}$ & 24 & 17 & 13 & 9 & 22 & 15 & 12 & 8 \\
\hline
\end{tabular}

filled with air or argon, and smaller than $15 \mathrm{~mm}$ if filled with $\mathrm{CO}_{2}$ or krypton. Xenon is even more demanding. In the case of upward heat flow, the cavities need to be nearly halved in size to achieve the same result. Generally, the diamond cavities must be smaller than the square ones, but the difference is not significant.

Table 8 displays how the value of $d_{\max }$ changes with the thickness of the GFP. At unchanging boundary conditions (Table 2), a thinner panel implies a greater temperature gradient and, consequently, more favourable conditions for the onset of convection. In order to prevent it, the cavities must therefore be smaller than in the thick panels.

\section{CONCLUSIONS}

The aim of this study was to introduce and assess the performance of a novel gas-filled panel (GFP) design based on a graphite polystyrene (GPS) core, with a metalized polyester envelope acting as a gas barrier. Numerical simulations of heat transfer were performed for different variations of the design - differing in the geometry of the GPS matrix, the gas filling, and the cavity surface emissivity - and for two heat flow directions - upward and horizontal. In each case the equivalent thermal conductivity of the panel was calculated to evaluate its thermal performance. Comparison of the results indicated how individual 
properties of the panel influence its performance and suggested their optimal combination. The numerical model was validated with standardised measurements of heat flow through a prototype GFP. Numerical simulations were also used to examine the influence of the cavity shape on the intensity of heat transfer. Square- and diamond-shaped cavities were considered. Finally, the optimal sizes in regard to convection were calculated for both cavity shapes, considering different gas fillings, heat flow directions and temperature gradients.

The research clearly demonstrates the two opposing effects caused by the presence of cavities in a GFP. On the one hand, they improve the panel's thermal performance because the conductivity of the gas filling is lower than that of GPS itself. On the other hand, the heat transfer through the cavity intensifies due to convection and radiation.

The study shows that GPS-based GFPs can exhibit thermal transmittances, up to $30 \%$ lower than that of GPS, however, two principal requirements must be met. Firstly, the conductivity of the gas filling must be significantly lower than the conductivity of GPS (e.g. $\mathrm{CO}_{2}$ or Ar), and secondly, low cavity surface emissivity $(\varepsilon=0.05)$ must be ensured. If the cavities are filled with air, which also fills the micro-pores of GPS, the GFP can barely surpass the performance of graphite polystyrene, even with the lowest emissivity. This suggests consideration of a different design - a GPS panel without cavities, but with micro-pores filled with a highly insulative gas.

Comparison of GFPs with square- and diamond-shaped cavities reveals that both geometries exhibit a similar thermal performance in all three forms of heat transfer (conduction, convection, radiation), especially if the cavities are small enough to prevent convection. The optimal cavity size, i.e. the largest to fulfil the last requirement, is approximately twice as big for the horizontal heat flow as it is for the upward heat flow. The actual value also depends on the temperature gradient and the gas filling. Carbon dioxide, being more prone to convection, demands approximately $25 \%$ smaller cavity sizes than air and argon.

In the present work it was assumed that the gas barrier was absolutely impermeable. In reality, however, a certain amount of the gas filling would leak through the protective sheath over time, reducing the thermal resistance of the GFP. Ageing analysis is beyond the scope of this study but the issue needs to be addressed in the future because excessive leaking could compromise the durability of the product.

Another point to be considered is the profitability. While the production cost cannot be precisely determined for the time being, it is evident that it could be relatively high compared to the plain GPS panel, due to both additional work and material. This suggests that the new product might be more appropriate for special cases of application, requiring its superior thermal performance. In the long term, the production cost should be reduced by the optimisation of the production process and the product itself.

To conclude, the GFPs based on a graphite polystyrene core with cavities offer an interesting alternative to conventional thermal insulation materials. Numerical simulations of heat transfer clearly indicate the possibility of substantial improvement of thermal performance. However, further research and development are required before the concept becomes a competitive commercial product.

\section{ACKNOWLEDGEMENTS}

This work was co-financed by the European Regional Development Fund and the Republic of Slovenia, Ministry of Education, Science and Sport under the Operational Programme for Implementing European Cohesion Policy 2014-2020. 


\section{REFERENCES}

[1] Berge, A. \& Johansson, P., Literature Review of High Performance Thermal Insulation, Chalmers University of Technology: Gothenburg, Sweden, 2012.

[2] Baetens, R., Jelle, B.P., Thue, J.V., Tenpierik, M.J., Grynning, S., Uvsløkk, S. \& Gustavsen, A., Vacuum insulation panels for building applications: A review and beyond. Energy and Buildings, 42(2), pp. 147-172, 2010. https://doi.org/10.1016/j. enbuild.2009.09.005

[3] Baetens, R., Jelle, B.P. \& Gustavsen, A., Aerogel insulation for building applications: A state-of-the-art review. Energy and Buildings, 43(4), pp. 761-769, 2011. https://doi. org/10.1016/j.enbuild.2010.12.012

[4] Griffith, B.T., Arasteh, D. \& Türler, D., Gas-filled panels: An update on applications in the building thermal envelope. Superinsulations and the Building Envelope, Proceedings of the BETEC Fall Symposium, pp. 1-13, 1995.

[5] Baetens, R., Jelle, B.P., Gustavsen, A. \& Grynning, S., Gas-filled panels for building applications: A state-of-the-art review. Energy and Buildings, 42(11), pp. 1969-1975, 2010. https://doi.org/10.1016/j.enbuild.2010.06.019

[6] Japelj Fir, M., Kralj, A., Žnidaršič, M. \& Remec, Č., S plinom polnjeni paneli za visokoizolacijske stavbne ovoje 21, stoletja. Gradbeni Vestnik, 61, pp. 159-167, 2012.

[7] Fi-Foil Company, www.gfpinsulation.com

[8] Coldpack, www.coldpack.com

[9] SIST EN ISO 10211:2017. Thermal bridges in building construction - Heat flows and surface temperatures - Detailed calculations. https://doi.org/10.3403/30143206u

[10] SIST EN ISO 10077-2:2017. Thermal performance of windows, doors and shutters - Calculation of thermal transmittance - Part 2: Numerical method for frames. https://doi.org/10.3403/30323247

[11] SIST EN 673:2011. Glass in building - Determination of thermal transmittance (U value) - Calculation method. https://doi.org/10.3403/02351907u_

[12] Incropera, F.P. \& DeWitt, D.P., Fundamentals of Heat and Mass Transfer, 4th edn., John Wiley \& Sons, 1996.

[13] SIST EN 12667:2002. Thermal performance of building materials and products - Determination of thermal resistance by means of guarded hot plate and heat flow meter methods - Products of high and medium thermal resistance. https://doi. org/10.3403/02152153u

[14] SIST EN ISO 10456:2008. Building materials and products - Hygrothermal properties - Tabulated design values and procedures for determining declared and design thermal values. https://doi.org/10.3403/30134452 